\title{
Avaliação de Meios de Cultura no Crescimento Micelial e Esporulação de Alternaria brasiliensis
}

\author{
Fátima M. Queiroz ${ }^{1}$, Ulisses G. Batista ${ }^{2}$ \& Sérgio H. Brommnschenkel ${ }^{2}$ \\ ${ }^{1}$ Diretoria de Pesquisa Agropecuária e Pesqueira, Secretaria Executiva de Agricultura, Irrigação, Pesca e Abastecimento, \\ Cx. Postal 99, CEP 57020-050, Maceió, AL; ²Departamento de Fitopatologia, Universidade Federal de Viçosa, \\ CEP 36570-000, Viçosa, MG
}

(Aceito para publicação em 15/04/2004)

Autor para correspondência: Fátima Maria Queiroz

QUEIROZ, F.M., BATISTA, U.G. \& BROMMONSCHENKEL, S.H. Avaliação de meios de cultura no crescimento micelial e esporulação de Alternaria brasiliensis. Fitopatologia Brasileira 29:541-543. 2004.

\begin{abstract}
RESUMO
O crescimento micelial e a esporulação de Alternaria brasiliensis foram avaliados em 20 meios de cultura. Para tanto, discos de $5 \mathrm{~mm}$ de diâmetro retirados da borda de colônia desenvolvida em V-8A3, após seis dias de incubação, a $25^{\circ} \mathrm{C}$, no escuro, foram repicados para placas de Petri contendo $15 \mathrm{ml}$ de cada meio. Sete dias após, mediu-se o crescimento micelial e quantificou-se a esporulação.

Verificou-se crescimento micelial de A. brasiliensis em todos os meios testados, embora esporulação só tenha ocorrido nos meios V-8A3, STA5 e SVA6. A maior quantidade de conídios foi produzida no meio V-8A3.

Palavras-chave adicionais: feijoeiro, mancha-de-Alternaria, fungo, esporulação.

ABSTRACT

Evaluation of culture media on the mycelial growth and sporulation of Alternaria brasiliensis

The mycelial growth and sporulation of the Alternaria brasiliensis were evaluated on 20 culture media. Five mm-diameter disks taken from the margins of colonies grown for six days on $\mathrm{V}$ $8 \mathrm{~A} 3$ medium at $25^{\circ} \mathrm{C}$ in the dark were transferred to Petri dishes

containing $15 \mathrm{ml}$ of each medium. After seven days, the mycelial growth and the sporulation were evaluated. Although mycelial growth of $A$. brasiliensis was observed on all tested media, sporulation was registered only on V-8A3, STA5 and SVA6. V$8 \mathrm{~A} 3$ was the best medium tested in this study for sporulation of the fungus.
\end{abstract}

O feijoeiro (Phaseolus vulgaris L.) está sujeito ao ataque de um grande número de patógenos que podem ser limitantes à produção. Entre eles, o fungo Alternaria brasiliensis Queiroz, Muniz \& Menezes, causador da mancha-de-Alternaria, que vem apresentando crescente importância econômica (Queiroz et al., 2001).

Nos últimos anos, sua ocorrência e severidade no município de Montanha, Estado do Espírito Santo, vem aumentando, devido, entre outros fatores, ao plantio de extensas áreas mecanizadas, sob irrigação por pivô central. Em decorrência de espécies de Alternaria esporularem irregularmente em cultura, a quantidade de inóculo produzida pode variar bastante dependendo da espécie, do isolado ou ainda das condições nutricionais (Simmons, 1992). Como conseqüência, a produção de esporos, normalmente é insuficiente para atender as inoculações em experimentos visando a seleção de fontes de resistência à doença.

Diversos meios de cultura que favorecem o crescimento micelial e estimulam a esporulação de espécies de Alternaria têm sido relatados na literatura. Entre eles, destacam-se o de batata-dextrose-ágar (Strider, 1978; Shahin \& Shepard, 1979; Hotchkiss \& Baxter, 1983; Cotty \& Misaghi, 1985 e Strandberg, 1987), o de batata-ágar (Fahim, 1966), o de V-8A(Strider, 1978; Strandberg, 1987 e Simmons, 1992), o de cenoura-ágar
(Hotchkiss \& Baxter, 1983) e o de folha de cenoura-ágar (Strandberg, 1987). Em decorrência destes fatos, buscou-se neste trabalho, selecionar meios de cultura que viessem favorecer o crescimento micelial e a esporulação do fungo $A$. brasiliensis, como suporte nas inoculações visando a identificação de fontes de resistência à doença.

O trabalho foi realizado no Laboratório de Fitopatologia da Universidade Federal de Viçosa, em Viçosa, MG, sendo o isolado de A. brasiliensis utilizado no estudo, obtido de folhas de feijoeiro, cv. Carioquinha, provenientes de Montanha, Espírito Santo (Queiroz, 1991).

Os 20 meios de cultura avaliados estão relacionados na Tabela 1. A maioria dos meios foram preparados de acordo com sua descrição na literatura (Tabela 1). No entanto, os meios V8A3, STA5 e SVA6 sofreram modificações conforme propostas por Miller (1955), Tuite (1969) e Del Peloso et al. (1989). Todos os meios foram autoclavados a $120^{\circ} \mathrm{C}$, por $20 \mathrm{~min}$, entretanto no meio SVA6, somente a mistura de 15,0 g de ágar; 3,0 g de $\mathrm{CaCO}_{3}$ e $1.000 \mathrm{ml}$ de água destilada foi autoclavada, sendo que $50 \mathrm{ml}$ de suco de vegetais Yakult foram acrescentados, assepticamente, momentos antes do meio ser vertido nas placas de Petri.

Para cada placa de Petri contendo $15 \mathrm{ml}$ de meio foi repicado um disco de $5 \mathrm{~mm}$ de diâmetro, retirado das bordas de 
F.M Queiroz et al.

TABELA 1 - Crescimento micelial e esporulação de Alternaria brasiliensis em 20 meios de cultura

\begin{tabular}{|c|c|c|c|}
\hline Meio de cultura & $\begin{array}{c}\text { Crescimento } \\
\text { micelial }^{\mathrm{a}}\end{array}$ & Esporulação $^{\mathrm{a}}$ & Referência \\
\hline Batata-dextrose-ágar (BDA) & + & - & Fahim, 1966 \\
\hline Batata-ágar (BA) & + & - & Fahim, 1966 \\
\hline BDA+Panvit & + & - & Del Peloso et al., 1989 \\
\hline BDA+extrato de folha de feijão & + & - & Santos Filho, 1976 \\
\hline $\mathrm{BA}+$ extrato de vagem & + & - & Santos Filho, 1976 \\
\hline Aveia-ágar & + & - & Tuite, 1969 \\
\hline Farinha de milho-ágar & + & - & Tuite, 1969 \\
\hline Folha de cenoura-ágar & + & - & Strandberg, 1987 \\
\hline Folha de feijão-ágar & + & - & Tuite, 1969 \\
\hline Sacarose-CaCO${ }_{3}$-ágar & + & - & Shahin \& Shepard, 1979 \\
\hline Suco de Cenoura-ágar & + & - & Hotchkiss \& Baxter,1983 \\
\hline Vagem-ágar & + & - & Tuite, 1969 \\
\hline Batata-folha de feijao-ágar & + & - & Santos Filho, 1976 \\
\hline $\mathrm{V}-8 \mathrm{~A}$ & + & - & Miller, 1955 \\
\hline V-8 a $15 \%-\mathrm{CaCO}_{3}$-ágar (V-8A1) & + & - & Modificado de Miller, 1955 \\
\hline V-8 a $10 \%-\mathrm{CaCO}_{3}$-ágar (V-8A2) & + & - & Modificado de Miller,1955 \\
\hline $\mathrm{V}-8$ a $5 \%-\mathrm{CaCO}_{3}$-ágar $(\mathrm{V}-8 \mathrm{~A} 3)$ & + & + & Modificado de Miller, 1955 \\
\hline Suco de tomate Temperado Superbom a $20 \%-\mathrm{CaCO}_{3}$-ágar (STA4) & + & - & Tuite, 1969 \\
\hline Suco de tomate Temperado Superbom a $5 \%-\mathrm{CaCO}_{3}$-ágar (STA5) & + & + & Modificado de Tuite, 1969 \\
\hline Suco de vegetal Yakult a $5 \%-\mathrm{CaCO}_{3}$ - ágar (SVA6) & + & + & Modificado de Del Peloso et al.,1989 \\
\hline
\end{tabular}

${ }^{a}$ Os sinais mais (+) e menos (-) representam crescimento micelial e esporulação positivos e negativos, respectivamente.

colônias desenvolvidas em meio V-8A3, durante seis dias, a $25^{\circ} \mathrm{C}$, no escuro.

As placas foram incubadas a $25^{\circ} \mathrm{C}$, com fotoperíodo de $12 \mathrm{~h}$ de luz negra, proporcionado por duas lâmpadas de 15 watts, marca Sylvania, F15T12/LN, dispostas $25 \mathrm{~cm}$ acima das placas. Após sete dias de crescimento, mediram-se os diâmetros das colônias e quantificou-se a esporulação nos diferentes meios. Para isso, foram adicionadas $10 \mathrm{ml}$ de água destilada, contendo Tween 80 a 0,05\% por placa de Petri, utilizando-se um pincel para facilitar a liberação dos conídios. A suspensão obtida foi filtrada em dupla camada de gaze e a concentração de conídios determinada ao microscópio.

$\mathrm{O}$ experimento seguiu delineamento inteiramente casualizado, com 20 tratamentos e oito repetições constituídas de uma placa de Petri. Pelos resultados observou-se crescimento micelial do fungo em todos os meios testados, embora esporulação só tenha sido registrada nos meios V8A3, STA5 e SVA6 (Tabela 1). Por isso mesmo, só foram efetuadas análises estatísticas para os três meios onde se registrou esporulação (Tabela 2).

O crescimento micelial e a esporulação de $A$. brasiliensis no meio V-8A3 foi significativamente superior ao dos meios STA5 e SVA6 (Tabela 2). Meios de cultura contendo na sua composição decoctos, extratos e sucos oriundos de folhas ou de partes vegetais normalmente estimulam o crescimento micelial e a esporulação de vários fungos (Dhingra \& Sinclair, 1985). Tal fato foi também observado com o fungo $A$. brasiliensis em relação aos meios semi-sintéticos contendo sucos de plantas e utilizados em baixas concentrações, os quais favoreceram a esporulação do fungo. Coty \& Misaghi (1985), utilizando suco V-8 em baixa concentração, também encontraram maior esporulação de A. tagetica, em meio de V-
TABELA 2 - Médias de crescimento micelial e esporulação de Alternaria brasiliensis em diferentes meios de cultura

\begin{tabular}{lcc}
\hline \hline Meio de cultura & $\begin{array}{c}\text { Crescimento micelial } \\
(\mathbf{m m})\end{array}$ & $\begin{array}{c}\text { Esporulação } \\
\text { Conídios } \mathbf{~} \mathbf{4} / \mathbf{m l}\end{array}$ \\
\hline V-8A3 & $54,70 \mathrm{a}^{*}$ & $11,67^{*} \mathrm{a}$ \\
STA5 & $42,90 \mathrm{~b}$ & $7,89 \mathrm{~b}$ \\
SVA6 & $30,60 \mathrm{c}$ & $4,94 \mathrm{c}$ \\
CV\% & 3,9 & 11,1 \\
\hline
\end{tabular}

*Médias seguidas pelas mesmas letras, numa mesma coluna, não diferem entre si, pelo teste de Tukey, a 5\% de probabilidade.

8A. Não obstante Strider (1978) e Strandberg (1987) obtiveram menor esporulação de A. dianthi e A. dauci, em meio V-8A. Tal fato poderia estar relacionado a fatores, inerentes à espécie do fungo ou à maior concentração de suco V-8 no meio. De acordo com Moore-Landecker (1972) meios de cultura contendo altas concentrações de nutrientes inibem a reprodução dos fungos, sem afetar o crescimento micelial.

\section{REFERÊNCIAS BIBLIOGRÁFICAS}

COTTY, P. J. \& MISAGHI, I. J. Effect of light on the behavior of Alternaria tagetica in vitro and in vivo. Phytopathology 75:366-370. 1985.

DEL PELOSO, M.C., FERNANDES, C.D., FILGUEIRAS, A.T. \& CHAVES, G.M. Esporulação de Cercospora coffeicola em diferentes meios de cultura. Fitopatologia Brasileira 14:41-44. 1989.

DHINGRA, O.D. \& SINCLAIR, J.B. Basic Plant Pathology Methods. Florida. CRC Press. 1985.

FAHIM, M.M. The effect of light and other factors on the sporulation of Alternaria porri. Transactions of the British Mycologycal Society 
49:73-78. 1986.

HOTCHKISS, E.S. \& BAXTER, L.W. Jr. Pathogenicity of Alternaria tagetica on Tagetes. Plant Disease 67:1288-1290. 1983.

MILLER, P.M. V-8 juice agar as a general purpose medium for fungi and bacteria. Phytopathology 45:461-462. 1955.

MOORE-LANDECKER, E. Fundamentals of the Fungi. London. Prentice-Hall. 1972.

QUEIROZ, F.M. Etiologia da mancha de alternária e reação de genótipos de feijoeiro à doença. (Tese de Mestrado). Viçosa. Universidade federal de Viçosa.1991.

QUEIROZ, F.M., MUNIZ, M. de F.S. \& MENEZES, M. Alternaria brasiliensis sp. nov., a leaf pathogen on Phaseolus vulgaris. Mycopathologia 150:61-65. 2001.

SANTOS FILHO, H.P. Isolamento e esporulação in vitro de Isariopsis griseola Sacc. (Tese de Mestrado). Viçosa. Universidade Federal de
Viçosa. 1976.

SHAHIN, E.A. \& SHEPARD, J.F. An efficient technique for inducing profuse sporulation of Alternaria species. Phytopathology 69:618620. 1979.

SIMMONS, E.G. Alternaria taxonomy: current status, viewpoint, challeng. In: Chalkowski, J. \& Visconti, A.C.J. (Eds.). AlternariaBiology, Plant Diseases \& Metabolites. Amsterdam. Elsevier. 1992. pp.1-35.

STRANDBERG, J.O. Isolation, storage, and inoculum production methods for Alternaria dauci. Phytopathology 77:1008-1012. 1987.

STRIDER, D.L. Alternaria blight of carnation in the greenhouse and its control. Plant Diseases Reporter 62:24-28. 1978.

TUITE, J. Plant Pathological Methods. Fungi and Bacteria. Minneapolis.Burgess Publish. Co. 1969. 